\title{
Front Matter: Volume 9570 (volume currently under technical review)
}

, "Front Matter: Volume 9570 (volume currently under technical review)," Proc. SPIE 9570, The Nature of Light: What are Photons? VI, 957001 (16 September 2015); doi: 10.1117/12.2208511

SPIE Event: SPIE Optical Engineering + Applications, 2015, San Diego, California, United States 


\title{
PROCEEDINGS OF SPIE
}

\section{The Nature of Light: What are Photons? VI}

\author{
Chandrasekhar Roychoudhuri \\ Al F. Kracklauer \\ Hans De Raedt \\ Editors
}

10-13 August 2015

San Diego, California, United States

Sponsored and Published by

SPIE 
The papers in this volume were part of the technical conference cited on the cover and title page. Papers were selected and subject to review by the editors and conference program committee. Some conference presentations may not be available for publication. Additional papers and presentation recordings may be available online in the SPIE Digital Library at SPIEDigitallibrary.org.

The papers reflect the work and thoughts of the authors and are published herein as submitted. The publisher is not responsible for the validity of the information or for any outcomes resulting from reliance thereon.

Please use the following format to cite material from this proceedings:

Author(s), "Title of Paper," in The Nature of Light: What are Photons? Vl, edited by Chandrasekhar Roychoudhuri, AI F. Kracklauer, Hans De Raedt, Proceedings of SPIE Vol. 9570 (SPIE, Bellingham, WA, 2015) Six-digit Article CID Number.

ISSN: 0277-786X

ISSN: 996-756X (electronic)

ISBN: 9781628417364

Published by

SPIE

P.O. Box 10, Bellingham, Washington 98227-0010 USA

Telephone +1 3606763290 (Pacific Time) · Fax +1 3606471445

SPIE.org

Copyright (c) 2015, Society of Photo-Optical Instrumentation Engineers.

Copying of material in this book for internal or personal use, or for the internal or personal use of specific clients, beyond the fair use provisions granted by the U.S. Copyright Law is authorized by SPIE subject to payment of copying fees. The Transactional Reporting Service base fee for this volume is $\$ 18.00$ per article (or portion thereof), which should be paid directly to the Copyright Clearance Center (CCC), 222 Rosewood Drive, Danvers, MA 01923. Payment may also be made electronically through CCC Online at copyright.com. Other copying for republication, resale, advertising or promotion, or any form of systematic or multiple reproduction of any material in this book is prohibited except with permission in writing from the publisher. The CCC fee code is 0277-786X/15/\$18.00.

Printed in the United States of America.

Publication of record for individual papers is online in the SPIE Digital Library.

\section{SPIE. DIGITAL}

SPIEDigitalLibrary.org

Paper Numbering: Proceedings of SPIE follow an e-First publication model. A unique citation identifier (CID) number is assigned to each article at the time of publication. Utilization of CIDs allows articles to be fully citable as soon as they are published online, and connects the same identifier to all online and print versions of the publication. SPIE uses a six-digit CID article numbering system structured as follows:

- The first four digits correspond to the SPIE volume number.

- The last two digits indicate publication order within the volume using a Base 36 numbering system employing both numerals and letters. These two-number sets start with 00, 01, 02, 03, 04, 05, 06, 07, 08, 09, OA, OB ... 0Z, followed by 10-1Z, 20-2Z, etc. The CID Number appears on each page of the manuscript. 


\title{
Contents
}

\author{
vii Authors \\ ix Conference Committee \\ xi Introduction
}

\section{SESSION 1 QUANTUM CONCEPTS/EPISTOMOLOGY I}

957002 Quantum theory as a description of robust experiments: application to Stern-Gerlach and Einstein-Podolsky-Rosen-Bohm experiments (Invited Paper) [9570-1]

957003 A convergence: special relativity, zitterbewegung, and new models for the subcomponent structure of quantum particles [9570-3]

957004 Classical explanations of results of quantum mechanics [9570-4]

957005 Photons as observer transitions in the event oriented world view [9570-5]

\section{SESSION 2 QUANTUM CONCEPTS/EPISTOMOLOGY ॥}

957006 Genesis of quantization of matter and radiation field (Invited Paper) [9570-6]

957007 Urgency of evolution process congruent thinking in physics [9570-7]

957008 What is a photon? [9570-8]

957009 Did Planck, Einstein, and Bose count indivisible photons or discrete emission/absorption processes in a black-body cavity? [9570-9]

\section{SESSION 3 WHAT IS A PHOTON I}

9570 OB Light dispersion in space [9570-11]

9570 OC The photon: EM fields, electrical potentials, and AC charge [9570-12]

9570 OD Electrons are spin 1/2 charged photons generating the de Broglie wavelength [9570-13]

$95700 \mathrm{E} \quad$ A study of the nature of light by comparing real and digital universes (Invited Paper) [9570-14] 
9570 OG Are there photons in fact? [9570-17]

$9570 \mathrm{OH} \quad$ Electron-positron annihilation and absorption models [9570-18]

9570 Ol An epitaph for all photons: a phoenix rising from its ashes (Invited Paper) [9570-19]

\section{SESSION 5 PARTICLE WAVE DUALITY I}

$9570 \mathrm{OL} \quad$ Wave interference: mechanics of the standing wave component and the illusion of "which way" information [9570-22]

\section{SESSION 6 PARTICLE WAVE DUALITY II}

$957000 \quad$ Mysterious quantum Cheshire cat: an illusion (Invited Paper) [9570-24]

9570 OP New experiments call for a continuous absorption alternative to the photon model [9570-25]

9570 OQ Quantum physics and the beam splitter mystery [9570-26]

9570 OR Photon diffraction described by momentum exchange theory: what more can edge diffraction tell us? [9570-27]

9570 OS The photon to electron/positron-pair transition [9570-28]

9570 OT Matter in the form of toroidal electromagnetic vortices [9570-29]

\section{SESSION 7 SPACE MEDIUM/NON-INTERACTION OF WAVES I}

9570 OV Could space be considered as the inertial rest frame? [9570-30]

9570 OY Light and harmonicity: the golden section [9570-33]

SESSION 8 SPACE MEDIUM/NON-INTERACTION OF WAVES II

$95700 Z$ Can the photon be described by a general particle model? [9570-34]

957010 Quantum mechanical probability current as electromagnetic 4-current from topological EM fields [9570-35] 
957013 The fine structure constant alpha: relevant for a model of a self-propelling photon and for particle masses (Invited Paper) [9570-38]

957014 The electron as a confined photon [9570-39]

957015 On the nature of the photon and the electron (Invited Paper) [9570-40]

957016 Absolute relativity in classical electromagnetism: the quantisation of light [9570-41]

SESSION 10 SPACE MEDIUM/NON-INTERACTION OF WAVES III

957018 Discovery of dynamical space: experiments and theory (Invited Paper) [9570-44]

957019 Energetic spacetime: the new aether [9570-45]

95701 A Modeling superposition of 3- and N-polarized beams on an isotropic photo detector [9570-46]

9570 1C Ring structures of atoms and molecules [9570-56]

\section{SESSION 11 SPACE MEDIUM/NON-INTERACTION OF WAVES IV}

9570 1D Clock time is absolute and universal (Invited Paper) [9570-48]

9570 IE Special relativity from observer's mathematics point of view [9570-49]

$95701 \mathrm{G}$ On the nature of "stuff" and the hierarchy of forces [9570-53]

PANEL DISCUSSION: ARE ELECTRONS OSCILLATING PHOTONS, OSCILLATING "VACUUM," OR SOMETHING ELSE?

957011 Are electrons oscillating photons, oscillating "vacuum," or something else? The 2015 panel discussion [9570-100] 
Proc. of SPIE Vol. $9570957001-6$

Downloaded From: https://www.spiedigitallibrary.org/conference-proceedings-of-spie on 26 Apr 2023 Terms of Use: https://www.spiedigitallibrary.org/terms-of-use 


\section{Authors}

Numbers in the index correspond to the last two digits of the six-digit citation identifier (CID) article numbering system used in Proceedings of SPIE. The first four digits reflect the volume number. Base 36 numbering is employed for the last two digits and indicates the order of articles within the volume. Numbers start with 00, 01, 02, 03, 04, 05, 06, 07, 08, 09, OA, OB...0Z, followed by 10-12, 20-2Z, etc.

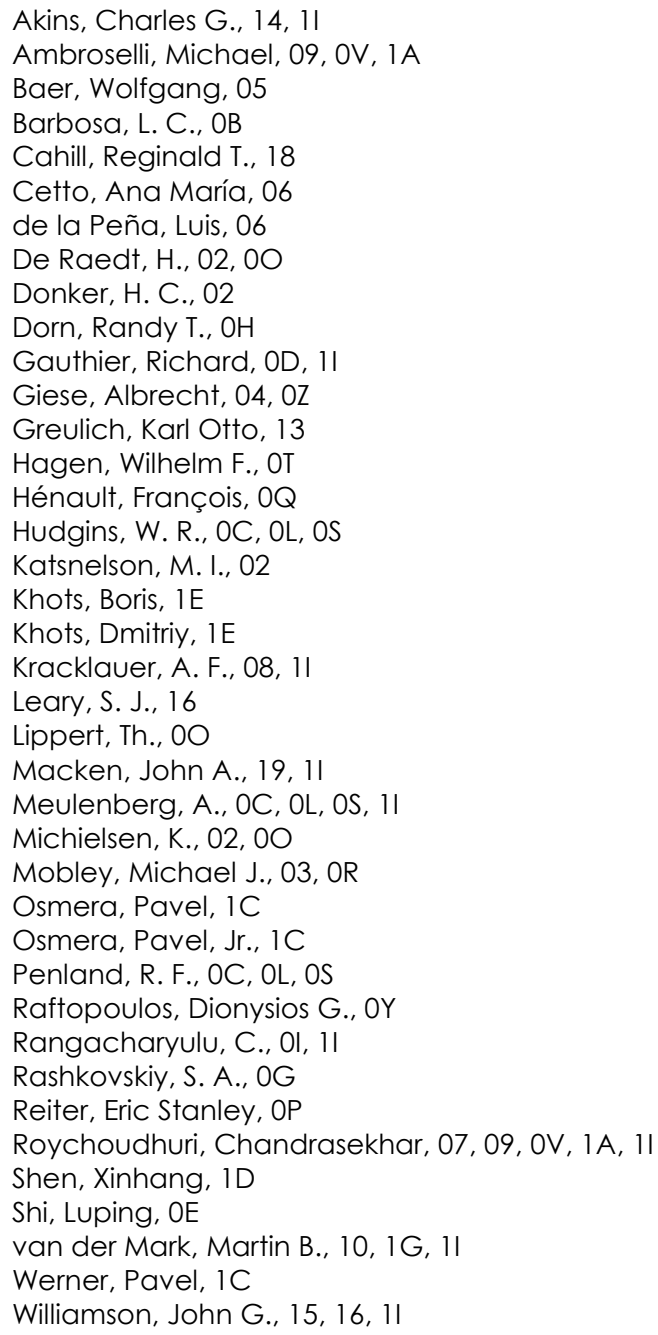


Proc. of SPIE Vol. $9570957001-8$

Downloaded From: https://www.spiedigitallibrary.org/conference-proceedings-of-spie on 26 Apr 2023 Terms of Use: https://www.spiedigitallibrary.org/terms-of-use 


\title{
Conference Committee
}

\author{
Conference Chairs
}

Chandrasekhar Roychoudhuri, University of Connecticut

(United States) and Femto Macro Continuum (United States)

Al F. Kracklaver, Consultant (Germany)

Hans De Raedt, University of Groningen (Netherlands)

\section{Conference Program Committee}

Michael Ambroselli, University of Connecticut (United States)

Antonio Badolato, University of Rochester (United States)

Ana María Cetto, Universidad Nacional Autónoma de México (Mexico)

Debashis Chanda, University of Central Florida (United States)

Luis de la Peña, Universidad Nacional Autónoma de México (Mexico)

Benjamin J. Eggleton, The University of Sydney (Australia)

Tepper L. Gill, Howard University (United States)

Karl Otto Greulich, Fritz Lipmann Institute (Germany)

Manuel Fernández-Guasti, Universidad Autónoma MetropolitanaIztapalapa (Mexico)

Habib Hamam, Université de Moncton (Canada)

François Hénault, Institut de Planétologie et d'Astrophysique de Grenoble, Université Joseph Fourier (France)

Subhash C. Kak, Oklahoma State University (United States)

Andrei Yu. Khrennikov, Linnaeus University (Sweden)

Akhlesh Lakhtakia, The Pennsylvania State University (United States)

Kristel F. Michielsen, Forschungszentrum Jülich GmbH (Germany)

John M. Myers, Harvard University (United States)

Narasimha S. Prasad, NASA Langley Research Center (United States)

Chary Rangacharyulu, University of Saskatchewan (Canada)

William T. Rhodes, Florida Atlantic University (United States)

Wolfgang P. Schleich, Universität Ulm (Germany)

Marlan O. Scully, Texas A\&M University (United States) and Princeton University (United States)

Luping Shi, Tsinghua University (China)

Riccardo C. Storti, Delta Group Engineering, P/L (Australia)

Din Ping Tsai, Academia Sinica (Taiwan)

Arnt Inge Vistnes, University of Oslo (Norway)

Ewan Malcolm Wright, College of Optical Sciences, The University of Arizona (United States) 


\section{Session Chairs}

1 Quantum Concepts/Epistomology I

Hans De Raedt, University of Groningen (Netherlands)

Albrecht Giese, Consultant (Germany)

2 Quantum Concepts/Epistomology II

Chandrasekhar Roychoudhuri, University of Connecticut (United States) and Femto Macro Continuum (United States)

Michael Ambroselli, University of Connecticut (United States)

3 What Is a Photon I

Richard Gauthier, Santa Rosa Junior College (United States)

Luping Shi, Tsinghua University (China)

4 What Is a Photon II

Chary Rangacharyulu, University of Saskatchewan (Canada)

Al F. Kracklauer, Consultant (Germany)

5 Particle Wave Duality I

Kristel F. Michielsen, Forschungszentrum Jülich GmbH (Germany)

Narasimha S. Prasad, NASA Langley Research Center (United States)

6 Particle Wave Duality II

François B. Hénault, Institut de Planétologie et d'Astrophysique de

Grenoble, Université Joseph Fourier (France)

Michael J. Mobley, Grand Canyon University (United States)

7 Space Medium/Non-Interaction of Waves I

Hans De Raedt, University of Groningen (Netherlands)

8 Space Medium/Non-Interaction of Waves II

Martin B. van der Mark, Philips Research Nederland B.V. (Netherlands)

Albrecht Giese, Consultant (Germany)

9 What Is a Photon III

Din Ping Tsai, Academia Sinica (Taiwan)

Karl Otto Greulich, Fritz Lipmann Institute (Germany)

10 Space Medium/Non-Interaction of Waves III

Narasimha S. Prasad, NASA Langley Research Center (United States)

Reginald T. Cahill, Flinders University (Australia)

11 Space Medium/Non-Interaction of Waves IV

Xinhang Shen, NAC Geographic Products Inc. (Canada)

Boris Khots, Compressor Controls Corporation (United States) 


\section{Introduction}

First, we must thank our committee members and all the authors for their time and effort to make this 6th biennial conference a great success. It is the active efforts of many members to seek out new valuable contributors that adds to the quality and recognition of this "special" conference series through its sustained growth. Of course, we must also thank the SPIE staff, whose professionalism is of critical importance to get everything done correctly and on time, in spite of innumerable demands from authors and chairs for immediate action.

Before highlighting this year's conference (Section-3), let us briefly outline the program of our 6th biennial conference held in August of 2015, in San Diego. The year 2015 has also been declared as the "Year of Light" by the Executive Board of UNESCO http://www.prweb.com/releases/2012/10/prweb10054327.htm. We welcome this declaration and will play our part by promoting a deeper understanding of the nature of light that overcomes the philosophical and cultural prejudices that are holding back enlightened thinking and consequent progress in physics and society at large. Those who are interested in developing web-based dialogues with their colleagues and highlighting their own epistemology are welcomed to visit the website: http://www.natureoflight.org/. Here, the video of Professor Marlan Scully's talk, given during the 6th biennial conference, can be viewed.

\section{Call for the 7th biennial conference}

While we have stayed on course with the ontological question, "What are photons?" from the standpoint of foundational thinking, we are actively soliciting participation from all major fields of physics (classical optics, quantum optics, relativity, cosmology, etc.). The two worlds of electromagnetism and material particles are inseparably intertwined. This is quite obvious from electron-positron pair production out of gamma rays and production of gamma rays out of electron-positron collisions. Optical science and engineering will start thriving faster once we understand the deeper physics behind light-matter interconvertibility. The expression "wave-particle-duality" and the related debate started more than 400 years ago with Newton and Huygens when this expression was understood as a lack of our understanding and raised deeper questions. Instead, over the last hundred years, our prevailing scientific culture has succeeded in elevating this lack of knowledge to a new knowledge! That is why the importance of this conference forum is timely, as is evidenced by the growing recognition of this conference series.

The significance of this forum also derives from historic pragmatic reality. Since ancient times, optical science and engineering have been providing us with key 
enabling tools (both incisive thinking and precision measuring instruments) to advance broader science and technologies.

\section{Brief history behind this conference series}

This "special" conference series was first held in the opportune year of 2005 when the whole world was celebrating the centennial celebration of "Einstein's Miracle Year!" We have just finished the 6th biennial conference and have started planning for the 7th biennial conference to be held in August 2017. All of you are strongly urged to participate with your outside-the-box ideas. Please, start soliciting your colleagues to join us in 2017.

For this 2015 conference, in this printed volume, we are publishing 38 papers out of 47 presented, with an original submission of 59 papers. Hopefully, the digital volume to be published this November should contain all the presented papers. During 2013, for the 5th conference, we had 52 papers published out of 64 papers submitted. In 2011, for the 4th conference, we published 56 out of 63 accepted papers. In 2009, we published 30 papers. In 2007, we published 31 papers. In 2005, for the first conference, we published 34 papers. The sustained improvements in the quality and the quantity of papers indicate that we are definitely meeting an important need of our scientific and engineering community. The rate of engineering innovations in a field goes up when the deeper physical meaning behind the relevant phenomena becomes clearer and accessible to more engineers.

\section{Brief summary of the content in this volume}

The readers will find the papers in this volume roughly follow the sessions categorized below.

Monday, 10 August 2015

Session 1: Quantum Concepts/Epistemology 1

Session 2: Quantum Concepts/Epistemology II

Tuesday, 11 August 2015

Session 3: What Is a Photon I

Session 4: What Is a Photon II

Session 5: Particle Wave Duality I

Session 6: Particle Wave Duality II

Technical Event: Tuesday Evening Keynote Talk by Prof. Marlan Scully: The Nature of Light: What are Photons? (To watch the video of this talk, go to: http://www.natureoflight.org/.)

Wednesday, 12 August 2015

Session 7: Space Medium/Non-Interaction of Waves I 
Session 8: Space Medium/Non-Interaction of Waves II

Session 9: What Is a Photon III

Session 10: Space Medium/Non-Interaction of Waves III

Thursday, 13 August 2015

Session 11: Space Medium/Non-Interaction of Waves IV

Panel Discussion: Are Electrons Oscillating Photons, Oscillating "Vacuum," or Something Different?

The panel discussion this year was very productive and animated. The panel summary can be found in this volume (Proceedings of SPIE Vol. 9570-100). Please, feel free to suggest new concepts for panel discussions. You can submit your suggestion by joining the web-group at: http://www.natureoflight.org/. This will allow a head-start for your suggested concept.

The nature of photons has been a mystery for many centuries, and this conference deepens that mystery, albeit through enlightening newer ideas. Those who are looking for rational, logical, consistent descriptions of observable phenomena in terms of concepts such as photons, electrons, protons, neutrons etc., might find inspiration in the outside-the-box thinking that is presented in the papers of this volume. Some papers address quantum concepts from very different perspectives. For instance, one paper starts by asking how sense impressions relate probabilities, a product of human thought, and shows that this mental process leads to quantum theoretical description, whereas other papers start from the assumption that there is an underlying objective reality. Yet another paper analyzes the EPR experiment and concludes that photons are more likely to be a mental construct rather than an ontic entity. There are several papers that focus on the nature of the photon, providing a wide variety of novel and yet logical approaches to understanding what photons and electromagnetic waves might be. Some of these papers propose that both photons and particles be represented by harmonic oscillations, thereby avoiding the need to introduce the concept of wave-particle duality. The latter is itself the subject of several papers which suggest various alternative pictures to set up a logical, mystery-free description of experimentally observed phenomena. Several papers also challenge the fundamental hypotheses behind relativity and gravitation. The idea that space itself might be regarded as a (dynamical) medium is scrutinized in several papers, again from different viewpoints and with quite diverse approaches. Some of these papers point out that the role of the observer has not been incorporated properly in the special theory of relativity. Others show that an extension of relativity can encompass both the free-field Maxwell equation and the Dirac equation and/or discuss the structure/topology of the solutions of such extended equations. 
The collection of papers and panel discussion in this volume clearly show that there is no indication that the foundation of physics is close to being finalized. Hence, we need your active participation to strengthen and broaden this outside-the-box platform to nurture inquiring minds set to explore the nature of light/matter and keep disseminating the new ideas freely expressed here.

Chandrasekhar Roychoudhuri

A. F. Kracklauer Hans De Raedt 